\title{
Effect of beta blocker use and type on hypoglycemia risk among hospitalized insulin requiring patients
}

Kathleen Dungan ${ }^{1 *}$, Jennifer Merrill${ }^{2}$, Clarine Long $^{3}$ and Philip Binkley ${ }^{4}$

\begin{abstract}
Background: Although beta blockers could increase the risk of hypoglycemia, the difference between subtypes on hypoglycemia and mortality have not been studied. This study sought to determine the relationship between type of beta blocker and incidence of hypoglycemia and mortality in hospitalized patients.

Methods: We retrospectively identified non-critically ill hospitalized insulin requiring patients who were undergoing bedside glucose monitoring and received either carvedilol or a selective beta blocker (metoprolol or atenolol). Patients receiving other beta blockers were excluded. Hypoglycemia was defined as any glucose $<3.9 \mathrm{mmol} / \mathrm{L}$ within $24 \mathrm{~h}$ of admission $\left(\mathrm{Hypo}_{1 \text { day }}\right)$ or throughout hospitalization $\left(\mathrm{Hypo}_{T}\right)$ and any glucose $<2.2 \mathrm{mmol} / \mathrm{L}$ throughout hospitalization ( $\left.\mathrm{Hypo}_{\text {severe }}\right)$.

Results: There were 1020 patients on carvedilol, 886 on selective beta blockers, and 10,216 on no beta blocker at admission. After controlling for other variables, the odds of $\mathrm{Hypo}_{1 \text { day, }}$, and selective beta blocker recipients than non-recipients, but only in basal insulin nonusers. The odds of $\mathrm{Hypo}_{1 \text { day }}$ (odds ratio $[\mathrm{OR}] 1.99,95 \%$ confidence interval $[\mathrm{Cl}] 1.28,3.09, \mathrm{p}=0.0002$ ) and $\mathrm{Hypo}_{\mathrm{T}}(\mathrm{OR} 1.38,95 \% \mathrm{Cl} 1.02,1.86$, $\mathrm{p}=0.03$ ) but not $\mathrm{Hypo}_{\text {severe }}(\mathrm{OR} 1.90,95 \% \mathrm{Cl} 0.90,4.02, \mathrm{p}=0.09$ ) were greater for selective beta blocker vs. carvedilol recipients in basal insulin nonusers. $\mathrm{Hypo}_{1 \text { day' }} \mathrm{Hypo}_{\mathrm{T}}$, and $\mathrm{Hypo}_{\text {severe }}$ were all associated with increased mortality in adjusted models among non-beta blocker and selective beta blocker recipients, but not among carvedilol recipients.

Conclusions: Beta blocker use is associated with increased odds of hypoglycemia among hospitalized patients not requiring basal insulin, and odds are greater for selective beta blockers than for carvedilol. The odds of hypoglycemiaassociated mortality are increased with selective beta blocker use or nonusers but not in carvedilol users, warranting further study.
\end{abstract}

Keywords: Hypoglycemia, Beta blocker, Diabetes mellitus, Hospitalized patients, Mortality

\section{Background}

The prevalence of hypoglycemia (defined as blood glucose $<3.9 \mathrm{mmol} / \mathrm{L}$ or $70 \mathrm{mg} / \mathrm{dL}$ ) is estimated to be $4.2 \%$ of all blood glucose measurements, or $3.5 \%$ of patient days in non-critically ill hospitalized patients in the United States [1]. Hypoglycemia is even more common among insulin-treated hospitalized patients [2]. Age,

\footnotetext{
*Correspondence: Kathleen.dungan@osumc.edu

${ }^{1}$ Division of Endocrinology, Diabetes \& Metabolism, The Ohio State University, 5th Floor McCampbell Hall, 1581 Dodd Drive, Columbus, $\mathrm{OH}$ 43210-1296, USA

Full list of author information is available at the end of the article
}

insulin dose, mistimed insulin doses, low body mass index, impaired renal function, and changes in diet or concomitant medications such as steroids are all potential contributing factors to hypoglycemic episodes among hospitalized patients with diabetes [3-5]. While the precise impact of iatrogenic hypoglycemia on hospital outcomes is debated, hypoglycemia is associated with increased length of stay, mortality and cost $[6,7]$.

Beta blockers (BB) are an essential component of guideline directed therapy for patients with heart failure and coronary artery disease, and are frequently used to treat hypertension. BB therapy is purported to increase 
the risk of severe or prolonged hypoglycemia by blunting the early adrenergic symptoms of impending hypoglycemia $[8,9]$. In particular, nonselective BB cause concern due to blockade of catecholamine-induced arterial vasodilation mediated by $\beta 2$ receptors resulting in unopposed $\alpha$-receptor stimulation during hypoglycemia $[10,11]$. However, other literature supports the general safety of $\beta-1$ selective blockade (SBB) in patients with diabetes [12]. In fact, BBs including the nonselective agent carvedilol, have been shown to prevent the expected impaired autonomic response to hypoglycemia known to follow an antecedent hypoglycemic event $[13,14]$. Moreover, in the presence of severe hypoglycemia, BB may decrease the risk of hypoglycemia-associated arrhythmias and death $[15,16]$.

However, there are few studies assessing the risk of BB use in acutely ill patients, in whom awareness of and counterregulatory responses to hypoglycemia may be impaired [17]. BBs have been associated with increased risk for cardiovascular events in patients with diabetes and heart disease, but it is unclear whether hypoglycemia or glucose lowering therapy plays a role [18]. In addition, many studies analyze the frequency of severe hypoglycemia, while non-severe events or even hypoglycemia unawareness can also have significant impact on wellbeing. Finally, it is unknown whether hypoglycemia risk and consequences differ by commonly used beta-blocker types. A large clinical trial that compared the metabolic effects of metoprolol (a selective inhibitor of $\beta 1$ receptors) to carvedilol (which inhibits $\beta 1, \beta 2$, and $\alpha 1$ receptors), carvedilol demonstrated more favorable effects on glycemic control and fewer hypoglycemia symptoms, though the authors note that the latter may be better explained by factors other than hypoglycemia [19]. Thus, the objective of this study is to determine the relationship between BB use and type with hypoglycemia and hypoglycemia-mediated mortality among hospitalized patients.

\section{Methods}

\section{Patient selection}

Patients over 18 years of age who were hospitalized between January 1, 2014 and December 31, 2015 with at least two blood glucoses per day (point of care or serum) and an order for subcutaneous insulin were identified from the study institution's Information Warehouse. The Information Warehouse is a data analysis tool that validates patient information from multiple sources. Exclusion criteria included intravenous insulin infusion, admission directly to the intensive care unit, or pregnancy. Intensive care settings were excluded as insulin is most often delivered intravenously in accordance with American Diabetes Association (ADA) standards of care [20]. Pregnant patients were excluded because of lower glycemic targets which are not generalizable to the rest of the inpatient population [21]. In order to accurately attribute risk and to distinguish risk between $\mathrm{BB}$ types, patients who initiated BB therapy after admission, switched $B B$ type during admission, or received a nonselective $\mathrm{BB}$ other than carvedilol were excluded. For patients with repeat admissions, one admission was chosen randomly for inclusion into the analysis. This was done to decrease potential bias and better capture the general inpatient population. Patients who have been admitted multiple times during a 2 year period are likely to be significantly more debilitated than a patient being admitted for the first time. The Ohio State University Institutional Review Board approved all study procedures.

\section{Clinical and laboratory variables}

Demographics, body mass index, Hemoglobin A1c during or within 30 days prior to admission, $\mathrm{BB}$ at admission, initial serum creatinine, service type (medical, surgical, cardiac), and concomitant medications were collected. Due to anticipated differential use of carvedilol vs. other $\mathrm{BB}$, heart failure was identified via the International Classification of Diseases (ICD), ICD-9 of 428.xx or ICD-10 of I50.xx). Diabetes diagnosis was identified as an ICD-9 250.xx or ICD-10 E08-13.xxxx on the active problem list. Basal insulin administration was defined as any order for glargine, detemir, $\mathrm{NPH}, 70 / 30,75 / 25$, or degludec at admission. In-hospital mortality was also collected as a clinical outcome.

Point of care and serum glucoses were collected and mean glucose was reported at admission, 24 and $72 \mathrm{~h}$. Definitions of hypoglycemia included glucose $<3.9 \mathrm{mmol} / \mathrm{L}(70 \mathrm{mg} / \mathrm{dL})$ within $24 \mathrm{~h}$ of admission $\left(\mathrm{Hypo}_{1 \text { day }}\right)$, or throughout the hospitalization $\left(\mathrm{Hypo}_{\mathrm{T}}\right)$. Severe hypoglycemia was defined as glucose $<2.2 \mathrm{mmol} / \mathrm{L}(40 \mathrm{mg} / \mathrm{dL})$ throughout the hospitalization $\left(\mathrm{Hypo}_{\text {Severe }}\right)$. The $3.9 \mathrm{mmol} / \mathrm{l}$ threshold is consistent with the typical threshold for treatment in the hospital and both $3.9 \mathrm{mmol} / \mathrm{L}$ and $2.2 \mathrm{mmol} / \mathrm{L}$ are definitions used by published studies of hospitalized patients and glucometric tools [5, 22-24].

\section{Glucose management}

At the study institution, patients with diabetes are generally managed with subcutaneous basal bolus insulin. Bolus insulin (lispro or aspart) is administered using order panels that specify low, standard, or high dose, corresponding to 1 unit per 20,10 , or $5 \mathrm{~g}$ of carbohydrates and 1 unit per 100,50 or $25 \mathrm{mg} / \mathrm{dL}$ above $150 \mathrm{mg} / \mathrm{dL}$ respectively. Target glucose range for inpatients is 140 $180 \mathrm{mg} / \mathrm{dL}$. Orders for point of care glucose monitoring 
prior to meals and bedtime accompany all subcutaneous insulin orders, with additional standing orders for glucose monitoring as needed for suspected hypoglycemia or hyperglycemia. Hospital guidelines provide tiered recommendations for management of hypoglycemia according to its severity, which includes oral carbohydrate administration (15-30 g) whenever possible and intravenous dextrose (12.5-25 g of 50\% dextrose) when a patient is unable to eat or is not neurologically intact. Follow-up glucose measurement is obtained and re-treatment occurs every 15 min until resolution of hypoglycemia. Point of care glucose was monitored using exact time stamps via the Nova StatStrip ${ }^{\circledR}$ glucometer. Meters are docked and downloaded at least daily and populate into to the electronic medical record.

\section{Analysis}

Continuous variables with normal distribution were reported as mean (standard deviation) and differences between groups were determined using the analysis of variance across groups and unpaired Student's T-test for comparisons between two groups. Continuous variables with non-normal distribution were reported as median (interquartile range) and analyzed using the Wilcoxon rank-sum test. Dichotomous variables were reported as number (percentage) and differences between groups were assessed using Chi square test. Statistical significance was considered at the threshold p-value less than 0.05 .

Multivariable logistic regression was performed for hypoglycemia occurrence as the dependent variable, and $\mathrm{BB}$ type (carvedilol, SBB, or none) as the primary independent variable. Covariates were selected based on previous knowledge as well as availability within the electronic medical record [25]. Separate models analyzing hospital mortality as dependent variables and hypoglycemia as the primary independent variable were created for carvedilol, SBB, or non-BB recipients. Analyses were performed using JMP 10.0 software.

\section{Results}

\section{Patient characteristics}

A total of 13,423 unique admissions met the initial inclusion criteria, of which 816 were patients who started BB after admission, 400 patients who switched BB after admission, and 171 patients who received nonselective $\mathrm{BB}$ other than carvedilol were excluded (patients may have been excluded for more than one reason). This left a final sample size of 1020 carvedilol, $886 \mathrm{SBB}$, and 10,216 non-BB recipients. Study population characteristics are shown in Table 1. BB recipients were older, less likely to be male or be on a surgery service, more likely to be on cardiac service, and had higher creatinine, hospital length of stay and frequency of basal insulin use (carvedilol 27\%, SBB 33\%, no BB 4.9\%, p<0.0001 by ANOVA), sulfonylurea/glinides, other cardiac medications and heart failure. Carvedilol users were less likely to be Caucasian than SBB or non-BB users while SBB were more likely to receive other diabetes medications.

Admission glucose and mean glucose at 24 and $72 \mathrm{~h}$ were similar in carvedilol, $\mathrm{SBB}$, and non-BB recipients (Table 1). Glucose coefficient of variation at 24 and $72 \mathrm{~h}$ was higher in carvedilol and SBB patients than non-BB recipients. Unadjusted frequency of $\mathrm{Hypo}_{1 \text { day }}, \mathrm{Hypo}_{\mathrm{T}}$, and $\mathrm{Hypo}_{\text {Severe }}$ were more common in carvedilol and SBB patients than non-BB recipients.

\section{Relationship between BB and hypoglycemia}

The unadjusted odds of all 3 definitions of hypoglycemia were increased for patients receiving carvedilol or SBB compared to no $\mathrm{BB}$ use (Table 2). Furthermore, the unadjusted odds of $\mathrm{Hypo}_{1 \text { day }}$ and $\mathrm{Hypo}_{\mathrm{T}}$, but not Hypo were higher in SSB compared to carvedilol recipients.

For all adjusted models, there was a strong interaction between basal insulin use and BB type and this interaction term was therefore included in all models. All logistic regression models were also adjusted for age, gender, race, body mass index, surgery service, admission glucose, admission creatinine, heart failure, and basal insulin at admission. The adjusted odds of $\mathrm{Hypo}_{1 \text { day }}$ (OR 4.66, 95\% confidence interval [CI] 3.616.01, p <0.0001), $\mathrm{Hypo}_{\mathrm{T}}$ (OR 12.1, 95\% CI 9.86-14.95, $\mathrm{p}<0.0001$ ), and $\mathrm{Hypo}_{\text {Severe }}$ (OR 3.56, 95\% CI 2.41-5.26, $\mathrm{p}<0.0001$ ) was increased in basal insulin nonusers compared to non-uers. The adjusted odds of $\mathrm{Hypo}_{1 \text { day }}$ were greater for carvedilol (odds ratio [OR] 1.45, 95\% CI 1.05$2.01, \mathrm{p}=0.0245$ ), and SBB (OR 1.78, 95\% CI 1.31-2.40, $\mathrm{p}=0.0002)$ compared to no $\mathrm{BB}$. There was no difference in odds for SBB compared to carvedilol (OR 1.22, 95\% CI $0.87-1.72, \mathrm{p}=0.25)$. The $\mathrm{p}$-value for interaction between $\mathrm{BB}$ category and basal insulin use was $<0.0001$.

For $\mathrm{Hypo}_{\mathrm{T}}$, the fully adjusted odds of hypoglycemia were greater for carvedilol (OR 2.56, 95\% CI 1.943.37, $\mathrm{p}<0.0001$ ) and SBB (OR 2.61, 95\% CI 2.05-3.33, $\mathrm{p}<0.0001)$ vs. no $\mathrm{BB}$. Further, the odds were similar for SBB vs. carvedilol (OR 1.02, 95\% CI 0.77-1.35, $\mathrm{p}=0.89$ ). The $\mathrm{p}$-value for interaction between $\mathrm{BB}$ category and basal insulin use was $<0.0001$.

For $\mathrm{Hypo}_{\text {Severe }}$, the fully adjusted odds of hypoglycemia were greater for carvedilol (OR 1.68, 95\% CI 1.03-2.74, $\mathrm{p}=0.04)$ and SBB (OR 1.70, 95\% CI 1.06-2.79, $\mathrm{p}=0.03$ ) compared to no BB. The odds were similar for SBB vs. carvedilol (OR 1.10, 95\% CI 0.59-1.75, $\mathrm{p}=0.97$ ). The $\mathrm{p}$-value for interaction between $\mathrm{BB}$ category and basal insulin use was $<0.0001$. 
Table 1 Baseline characteristics by BB status

\begin{tabular}{|c|c|c|c|c|}
\hline & $\begin{array}{l}\text { No BB } \\
(N=10,216)\end{array}$ & $\begin{array}{l}\text { Carvedilol } \\
(\mathrm{N}=1020)\end{array}$ & $\begin{array}{l}\text { SBB } \\
(N=886)\end{array}$ & $\mathrm{p}$-value \\
\hline Age, years & $60(15)$ & $64(13)$ & $65(13)$ & $<0.0001$ \\
\hline Male, N (\%) & $4986(49)$ & $381(37)$ & $383(43)$ & $<0.0001$ \\
\hline Race, N (\%) & & & & $<0.0001$ \\
\hline Caucasian & $7422(73)$ & $628(62)$ & $689(78)$ & - \\
\hline African & $2293(22)$ & $357(35)$ & $174(20)$ & - \\
\hline Asian & $121(1.2)$ & $10(1.0)$ & $4(0.45)$ & - \\
\hline American Indian & $20(0.20)$ & $1(0.10)$ & $0(0)$ & - \\
\hline Middle Eastern & $28(0.27)$ & $2(0.20)$ & $2(0.23)$ & - \\
\hline Other & $332(3.3)$ & $22(2.2)$ & $17(1.9)$ & - \\
\hline Body mass index, $\mathrm{kg} / \mathrm{m}^{2}$ & $33.1(9.4)$ & $33.7(9.6)$ & $33.4(9.6)$ & 0.13 \\
\hline Surgery service, N (\%) & $2837(28)$ & $72(7.1)$ & $140(16)$ & $<0.0001$ \\
\hline Cardiac service, N (\%) & $1330(13)$ & $401(39)$ & $352(30)$ & $<0.0001$ \\
\hline Hemoglobin A1c, \% & $\begin{array}{l}7.98(2.53) \\
N=1704\end{array}$ & $\begin{array}{l}7.71(2.14) \\
N=186\end{array}$ & $\begin{array}{l}7.78(2.30) \\
N=113\end{array}$ & 0.30 \\
\hline Admission creatinine, $\mu \mathrm{mol} / \mathrm{L}$ & $1.40(1.50)$ & $2.24(2.14)$ & $1.63(1.46)$ & $<0.0001$ \\
\hline Hospital length of stay, days & $4(3-7)$ & $6(4-10)$ & $6(4-11)$ & $<0.0001$ \\
\hline Basal insulin at admission, $\mathrm{N}(\%)$ & $500(4.9)$ & $272(27)$ & $292(33)$ & $<0.0001$ \\
\hline Heart failure, N (\%) & $461(4.5)$ & $814(80)$ & $459(52)$ & $<0.0001$ \\
\hline Sulfonylurea/glinide & $25(0.24)$ & $40(3.9)$ & $31(3.5)$ & $<0.0001$ \\
\hline Other glucose lowering agents (non-insulin, non-sulfonylurea/glinide) & $67(0.66)$ & $95(0.93)$ & $61(6.9)$ & $<0.0001$ \\
\hline ACE inhibitor/ARB & $171(1.7)$ & $515(50)$ & $278(31)$ & $<0.0001$ \\
\hline Statin & $340(3.3)$ & $692(68)$ & $395(45)$ & $<0.0001$ \\
\hline Aspirin & $361(3.5)$ & $698(68)$ & $397(45)$ & $<0.0001$ \\
\hline \multicolumn{5}{|l|}{ Mean glucose (mmol/L) } \\
\hline Admission & $175(95)$ & $175(92)$ & $168(87)$ & 0.11 \\
\hline $24 \mathrm{~h}$ & $167(61)$ & $167(62)$ & $165(59)$ & 0.75 \\
\hline $72 \mathrm{~h}$ & $164(47)$ & $164(47)$ & $162(46)$ & 0.51 \\
\hline \multicolumn{5}{|l|}{ Hypoglycemia, N (\%) } \\
\hline$<3.9 \mathrm{mmol} / \mathrm{L}$ (70 mg/dL), first $24 \mathrm{~h}$ & $497(4.9)$ & $138(13.5)$ & $151(17)$ & $<0.0001$ \\
\hline$<3.9 \mathrm{mmol} / \mathrm{L}$ (70 mg/dL), during hospital stay & $1194(12)$ & $393(38)$ & $441(50)$ & $<0.0001$ \\
\hline$<2.2 \mathrm{mmol} / \mathrm{L},(40 \mathrm{mg} / \mathrm{dL})$, during hospital stay & $132(1.3)$ & $47(4.6)$ & $43(4.9)$ & $<0.0001$ \\
\hline Events $<3.9 \mathrm{mmol} / \mathrm{L}(70 \mathrm{mg} / \mathrm{dL}) /$ day during hospital stay & $0(0.0)$ & $0(0.17)$ & $0(0.025)$ & $<0.0001$ \\
\hline \multicolumn{5}{|l|}{ Glucose coefficient of variation (\%) } \\
\hline $24 \mathrm{~h}$ & $0.22(0.13)$ & $0.26(0.15)$ & $0.26(0.15)$ & $<0.0001$ \\
\hline $72 \mathrm{~h}$ & $0.24(0.11)$ & $0.29(0.13)$ & $0.28(0.12)$ & $<0.0001$ \\
\hline
\end{tabular}

Continuous variables that are normally distributed are reported as mean (standard deviation) and analyzed with the analysis of variance. Continuous variables that are not normally distributed are reported as median (interquartile range [IQR]) and analyzed using Wilcoxon Rank-sum. Dichotomous variables are presented using number (percentage) and analyzed using the Chi-square test

$B B$ beta blocker, $S B B$ selective beta blocker

Due to the interaction by basal insulin use, separate models were created for basal insulin users and nonusers. For $\mathrm{Hypo}_{1 \text { day }}$ the fully adjusted odds of hypoglycemia were greater for basal insulin non-users but not for basal insulin users (Table 2). Moreover, there were greater odds of hypoglycemia associated with SBB vs. carvedilol in basal insulin non-users (OR 1.99, 95\% CI $1.28-3.09, \mathrm{p}=0.0003$ ) but not in users (OR 0.70, 95\% CI $0.41-1.18, \mathrm{p}=0.46)$. Likewise, for $\mathrm{Hypo}_{\mathrm{T}}$ the fully adjusted odds of hypoglycemia were greater for basal insulin non-users but not for basal insulin users. Further, there was a greater odds of hypoglycemia associated with SBB vs. carvedilol in basal insulin non-users (OR 1.38, 95\% CI 1.02-1.86, $\mathrm{p}=0.03$ ) but not in users (OR 0.84, 95\% CI 0.52-1.36, $\mathrm{p}=0.47$ ). Similarly, for Hypo $_{\text {Severe the fully adjusted odds of hypoglycemia }}$ were greater for basal insulin non-users but not for basal insulin users. The odds of hypoglycemia associated with SBB vs. carvedilol was not significantly different in basal insulin non-users (OR 1.90, 95\% CI 
Table 2 Relationship between beta blocker use and hypoglycemia

\begin{tabular}{|c|c|c|c|c|c|c|c|c|c|c|}
\hline & \multicolumn{4}{|c|}{ Overall } & \multicolumn{3}{|c|}{ No basal insulin } & \multicolumn{3}{|c|}{ Basal insulin } \\
\hline & OR & $95 \% \mathrm{Cl}$ & p-value & 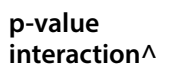 & OR & $95 \% \mathrm{Cl}$ & p-value & OR & $95 \% \mathrm{Cl}$ & p-value \\
\hline \multicolumn{11}{|c|}{ Odds ratio for glucose $<3.9 \mathrm{mmol} / \mathrm{L}(70 \mathrm{mg} / \mathrm{dL})$ within $24 \mathrm{~h}$} \\
\hline \multicolumn{11}{|l|}{ Unadjusted model } \\
\hline Carvedilol vs. none & 3.01 & $2.48-3.71$ & $<0.0001$ & - & 2.56 & $1.95-3.37$ & $<0.0001$ & 0.91 & $0.65-1.27$ & 0.58 \\
\hline SBB vs. none & 4.02 & $3.30-4.89$ & $<0.0001$ & & 4.96 & $3.89-6.33$ & $<0.0001$ & 0.62 & $0.44-0.88$ & 0.008 \\
\hline SBB vs carvedilol & 1.32 & $1.03-1.70$ & 0.03 & & 1.94 & $1.39-2.70$ & 0.0001 & 0.68 & $0.46-1.02$ & 0.06 \\
\hline \multicolumn{11}{|l|}{ Adjusted model } \\
\hline Carvedilol vs. none & 1.45 & $1.05-2.01$ & 0.0245 & $<0.0001$ & 2.15 & $1.38-3.37$ & 0.0007 & 1.18 & $0.74-1.90$ & 0.49 \\
\hline SBB vs. none & 1.78 & $1.31-2.40$ & 0.0002 & & 4.29 & $2.96-6.20$ & $<0.0001$ & 0.82 & $0.51-1.32$ & 0.42 \\
\hline SBB vs. carvedilol & 1.22 & $0.87-1.72$ & 0.25 & & 1.99 & $1.28-3.09$ & 0.0023 & 0.70 & $0.41-1.18$ & 0.18 \\
\hline \multicolumn{11}{|c|}{ Odds ratio for glucose $<3.9 \mathrm{mmol} / \mathrm{L}(70 \mathrm{mg} / \mathrm{dL})$ overall } \\
\hline \multicolumn{11}{|l|}{ Unadjusted model } \\
\hline Carvedilol vs. none & 4.72 & $4.10-5.42$ & $<0.0001$ & - & 3.39 & $2.82-4.09$ & $<0.0001$ & 1.05 & $0.72-1.51$ & 0.81 \\
\hline SBB vs. none & 7.49 & $6.48-8.66$ & $<0.0001$ & & 6.30 & $5.25-7.56$ & $<0.0001$ & 0.91 & $0.64-1.29$ & 0.58 \\
\hline SBB vs. carvedilol & 1.59 & $1.32-1.90$ & $<0.0001$ & & 1.86 & $1.46-2.35$ & $<0.0001$ & 0.87 & $0.58-1.30$ & 0.48 \\
\hline \multicolumn{11}{|l|}{ Adjusted model } \\
\hline Carvedilol vs. none & 2.56 & $1.94-3.37$ & $<0.0001$ & $<0.0001$ & 6.30 & $4.59-8.65$ & $<0.0001$ & 1.03 & $0.65-1.63$ & 0.91 \\
\hline SBB vs. none & 2.61 & $2.05-3.33$ & $<0.0001$ & & 8.69 & $6.57-11.5$ & $<0.0001$ & 0.86 & $0.56-1.31$ & 0.48 \\
\hline SBB vs. carvedilol & 1.02 & $0.77-1.35$ & 0.89 & & 1.38 & $1.02-1.86$ & 0.03 & 0.84 & $0.52-1.36$ & 0.47 \\
\hline \multicolumn{11}{|c|}{ Odds ratio for glucose $<2.2 \mathrm{mmol} / \mathrm{L}(40 \mathrm{mg} / \mathrm{dL}$ ) overall } \\
\hline \multicolumn{11}{|l|}{ Unadjusted model } \\
\hline Carvedilol vs. none & 3.69 & $2.62-5.18$ & $<0.0001$ & - & 2.63 & $1.50-4.60$ & 0.0007 & 1.04 & $0.65-1.64$ & 0.88 \\
\hline SBB vs. none & 3.90 & $2.74-5.54$ & $<0.0001$ & & 6.12 & $3.91-9.58$ & $<0.0001$ & 0.45 & $0.25-0.80$ & 0.007 \\
\hline SBB vs. carvedilol & 1.06 & $0.69-1.61$ & 0.80 & & 2.33 & $1.23-4.43$ & 0.0098 & 0.43 & $0.23-0.81$ & 0.009 \\
\hline \multicolumn{11}{|l|}{ Adjusted model } \\
\hline Carvedilol vs. none & 1.68 & $1.03-2.74$ & 0.04 & $<0.0001$ & 3.21 & $1.49-6.91$ & 0.0029 & 1.11 & $0.58-2.10$ & 0.76 \\
\hline SBB vs. none & 1.70 & $1.06-2.75$ & 0.03 & & 6.11 & $3.37-11.1$ & $<0.0001$ & 0.56 & $0.26-1.20$ & 0.13 \\
\hline SBB vs. carvedilol & 1.10 & $0.59-1.75$ & 0.97 & & 1.90 & $0.90-4.02$ & 0.09 & 0.50 & $0.22-1.14$ & 0.10 \\
\hline
\end{tabular}

All adjusted models adjusted for age, gender, race, body mass index*, surgery service, admission glucose*, admission creatinine*, basal insulin use, heart failure, hospital length of stay, cardiovascular service, statin, aspirin, ACE/ARB, $\wedge$ basal insulin by BB type interaction. ${ }^{*}$ log transformed values

$B B$ beta blocker, SBB selective beta blocker

$0.90-4.02, \mathrm{p}=0.09)$ or users (OR $0.50,95 \%$ CI $0.22-$ $1.14, \mathrm{p}=0.10)$.

Due to the observation that patients with heart failure were more likely to receive carvedilol compared to $\mathrm{SBB}$, a sensitivity analysis was conducted among heart failure subgroups (Additional file 1: Table S1). In fully adjusted models, both carvedilol and SBB were associated with increased odds of $\mathrm{Hypo}_{1 \text { day }}, \mathrm{Hypo}_{\mathrm{T}}$, and $\mathrm{Hypo}_{\text {Severe }}$ in patients without heart failure, but not in patients with heart failure. There was no significant difference in odds of any of the hypoglycemia measures in carvedilol vs. SBB recipients in either subgroup.

\section{Relationship between hypoglycemia and hospital mortality}

$\mathrm{Hypo}_{1 \text { day }}$ was associated with increased adjusted odds of in-hospital mortality in non-BB recipients (OR 2.10, 95\%
CI 1.15-3.86, $\mathrm{p}=0.016)$ but not among carvedilol $(0.79$, $95 \%$ CI $0.15-4.10, \mathrm{p}=0.78$ ) or SBB (OR 1.67, 95\% CI $0.54-5.16, \mathrm{p}=0.37$ ) recipients (Table 3 ).

In contrast, $\mathrm{Hypo}_{\mathrm{T}}$ was associated with higher adjusted odds of in-hospital mortality in both non-BB (OR 1.80, 95\% CI 1.16-2.80, $\mathrm{p}=0.009)$ and SBB (OR 4.89, 95\% CI 1.76-13.6, $\mathrm{p}=0.002$ ), but not carvedilol (OR 1.55, 95\% CI $0.49-4.95, \mathrm{p}=0.46$ ) recipients (Table 3 ).

In a separate model that included only $\mathrm{BB}$ recipients, there was no interaction between hypoglycemia $(<3.8 \mathrm{mmol} / \mathrm{L})$ and $\mathrm{BB}$ type on the odds of mortality. However, data are not shown due to unstable estimates.

Likewise, Hypo Severe $_{\text {was }}$ associated with increased adjusted odds of in-hospital mortality in both non-BB (OR 3.74, 95\% CI 1.48-9.46, $\mathrm{p}=0.005$ ), and SBB (OR 10.6, 95\% CI 3.27-34.3, p <0.0001), but not carvedilol (OR 1.94, 95\% CI 0.36-10.3, $\mathrm{p}=0.44$ ) recipients. 
Table 3 Relationship between hypoglycemia and mortality in beta blocker subgroups

\begin{tabular}{|c|c|c|c|c|c|c|c|c|c|}
\hline & \multicolumn{3}{|c|}{ Non-recipients of beta blockers } & \multicolumn{3}{|c|}{ Carvedilol recipients } & \multicolumn{3}{|c|}{ Selective beta blocker recipients } \\
\hline & OR & $95 \% \mathrm{Cl}$ & p-value & OR & $95 \% \mathrm{Cl}$ & p-value & OR & $95 \% \mathrm{Cl}$ & p-value \\
\hline \multicolumn{10}{|c|}{ Odds ratio for mortality in patients with vs. those without hypoglycemia $(<3.9 \mathrm{mmol} / \mathrm{L})$ within $24 \mathrm{~h}$ of admission } \\
\hline Unadjusted model & 2.40 & $1.56-3.71$ & $<0.001$ & 0.83 & $0.25-2.81$ & 0.77 & 1.60 & $0.74-3.46$ & 0.23 \\
\hline Adjusted model & 2.10 & $1.15-3.86$ & 0.016 & 0.79 & $0.15-4.10$ & 0.78 & 1.67 & $0.54-5.16$ & 0.37 \\
\hline \multicolumn{10}{|c|}{ Odds ratio for mortality in patients with vs. those without hypoglycemia $(<3.9 \mathrm{mmol} / \mathrm{L})$ overall } \\
\hline Unadjusted model & 2.21 & $1.60-3.04$ & $<0.0001$ & 1.18 & $0.54-2.60$ & 0.68 & 2.17 & $1.08-4.37$ & 0.03 \\
\hline Adjusted model & 1.80 & $1.16-2.80$ & 0.009 & 1.55 & $0.49-4.95$ & 0.46 & 4.89 & $1.76-13.56$ & 0.002 \\
\hline \multicolumn{10}{|c|}{ Odds ratio for mortality in patients with vs. those without hypoglycemia $(<2.2 \mathrm{mmol} / \mathrm{L})$ overall } \\
\hline Unadjusted model & 4.63 & $2.52-8.52$ & $<0.0001$ & 1.76 & $0.40-7.67$ & 0.45 & 6.42 & $2.73-15.1$ & $<0.0001$ \\
\hline Adjusted model & 3.74 & $1.48-9.46$ & 0.005 & 1.94 & $0.36-10.3$ & 0.44 & 10.6 & $3.27-34.3$ & $<0.0001$ \\
\hline
\end{tabular}

Adjusted model includes age, gender, race, body mass index*, surgery service, admission glucose*, admission creatinine*, hospital length of stay*, basal insulin, heart failure, cardiovascular service, statin, aspirin, ACE/ARB and hypoglycemia ( $<70 \mathrm{mg} / \mathrm{dL}$ within $24 \mathrm{~h},<70$ during entire hospitalization, or $<40 \mathrm{mg} / \mathrm{dL}$ during entire hospitalization. ${ }^{*}$ log transformed values

There was no significant interaction by basal insulin use in these models. However, these models demonstrated unstable estimates and therefore were not presented.

\section{Discussion}

\section{Major findings}

In this analysis, the adjusted odds of hypoglycemia within the first $24 \mathrm{~h}$ of admission and total or severe hypoglycemia throughout the admission were increased with $\mathrm{BB}$ use. However, there was a significant interaction by basal insulin use such that hypoglycemia was only increased in patients who were not using basal insulin. In addition the odds of hypoglycemia were increased with SBB compared to carvedilol, again only in basal insulin users. Carvedilol and SBB were associated with increased risk of hypoglycemia in patients without heart failure but not in patients with heart failure. Finally, hypoglycemia was associated with increased odds of mortality in BB nonrecipients and SBB recipients but not with carvedilol use.

\section{BB and hypoglycemia risk}

There are few data describing risk of hypoglycemia among hospitalized BB recipients who are receiving insulin. A recent large inpatient analysis identified risk factors for hypoglycemia, but did not report BB use [26]. Cardona and colleagues [27] did not identify a difference in risk according to $\mathrm{BB}$ use, but the study was much smaller $(\mathrm{N}=250)$. In the ambulatory setting, there is also low quality evidence assessing the risk of hypoglycemia with $\mathrm{BB}$ use [12]. A recent study did not find increased readmission rate for elderly nursing home patients after acute myocardial infarction with nonselective BB compared to SBB [28]. Among insulin- or sulfonylurea-requiring patients, SBB was not associated with increased risk of serious hypoglycemia compared to nonusers $[29,30]$. Similarly, in this study, $\mathrm{BB}$ use was associated with hypoglycemia among basal insulin nonusers, but not among basal insulin users. While we can not determine the extent or duration of insulin use prior to admission, it is possible that basal insulin use represents patients with previous or longer duration of insulin use. It has been reported that duration of insulin use [31], and increasing complexity of insulin regimens [32], are associated with increased risk of hypoglycemia and hypoglycemia unawareness. In rat models of cardiac ischemia and reperfusion, hearts from animals with diabetes but not hearts from animals without diabetes were amenable to cardioprotection due to ischemic preconditioning during hypoglycemia [33]. Thus BB use may not be relevant in patients with long-standing insulin use, some of whom may already have loss of early counterregulatory responses or frank hypoglycemia unawareness [34]. Moreover, while acute $\mathrm{BB}$ administration may attenuate the loss of counterregulatory responses induced by antecedent hypoglycemia, the long-term effects are less clear, and in this study, only chronic BB use was included [13]. Thus, more research is needed to investigate the effects of long-term $\mathrm{BB}$ use and its interaction with insulin use.

\section{Role of BB type}

The odds of hypoglycemia were slightly greater with SBB than with carvedilol in this study. This finding remains unexplained, but could be related to differences in $\beta$-receptor and $\alpha$-receptor activity and the attendant autonomic responses to hypoglycemia [35]. This was the rationale for excluding other $\mathrm{BB}$, which were few in number and had other unique characteristics. For example, propranolol, also a nonselective $\mathrm{BB}$, has been reported to result in adverse hemodynamic effects during 
hypoglycemia, possibly due to unopposed $\alpha-1$ receptor activity $[10,11]$, and more severe hypoglycemic events compared to SBB $[30,36]$. Therefore, SBB are generally recommended in patients requiring concomitant insulin. However, the current results suggest that this recommendation may not apply to all nonselective BBs. Carvedilol has $\alpha-1$ receptor blocking effects and may therefore mitigate the adverse effects observed with propranolol. While previous studies demonstrate that adrenergic responses to experimentally induced hypoglycemia are mediated by the $\beta$-receptors (not $\alpha$-receptors), responses to experimentally derived hypoglycemia may not adequately reflect counterregulatory responses in chronic use or in severe illness [37]. For example, multiple stressors can cause opioid receptor activation, in part via $\alpha-1$ receptors in the adrenal gland, which in turn may impair hypoglycemia counterregulation [38, 39]. Moreover, carvedilol use is associated with lower hypoglycemia symptom scores and a favorable metabolic profile compared to metoprolol [19], which may influence insulin requirements and hypoglycemia [40, 41]. In this study, carvedilol and SBB recipients were more likely to receive basal insulin than non-BB users. However, it is unlikely that basal insulin use influenced $\mathrm{BB}$ prescribing practices, as insulin use was similar among carvedilol or SBB recipients. Finally, it is possible that residual confounding by indication may explain the results, particularly since tolerability of carvedilol may lessen with more severe illness, such as advanced heart failure. A separate analysis by heart failure status did not confirm the increase in risk of hypoglycemia in patients without heart failure receiving SBB compared to carvedilol but the sample size may be too small to draw conclusions $(\mathrm{N}=206$ carvedilol, $\mathrm{N}=427$ SBB).

\section{$\mathrm{BB}$ and heart failure}

Carvedilol and SBB decrease long-term mortality in heart failure [42, 43]. Despite this, clinicians have historically been hesitant to prescribe BB to patients with diabetes and heart disease due to concern for adverse effects [44]. In the present study, carvedilol and SBB were associated with increased risk of hypoglycemia in patients without heart failure but not in patients with heart failure. The reduction in hypoglycemia-associated autonomic failure due to BB use offers a potential mechanism [14]. A secondary analysis of the ACCORD trial found increased mortality in patients with cardiovascular disease and diabetes treated with $\mathrm{BB}$, however it did not identify the types of BB used by study participants [8]. Further research is needed to determine the relationship of beta blockade and hypoglycemia in patients with comorbid diabetes and HF.

\section{Mortality}

Hypoglycemia was associated with increased mortality in non-BB patients and SBB users, but not in carvedilol users. This finding is in line with the findings observed for hypoglycemia, though is insufficient to establish a causal relationship between hypoglycemia and mortality. In the ambulatory environment, $\mathrm{BB}$ use is associated with mortality and cardiovascular events in patients with diabetes $[8,18]$, though not in older studies [45], possibly due to better control of other risk factors in more recent literature. Nevertheless, BBs appeared to be protective of the increase in all-cause and cardiovascular death observed with intensive glycemic control in the ACCORD trial [15]; however BB type and insulin use was not analyzed separately in any of these studies. The present findings are consistent with a recent observational study of outpatients, which found that SBB but not nonselective BB were associated with a possible reduction in mortality in patients with episodes of hypoglycemia [46]. In another study of older nursing home patients discharged after myocardial infarction, there was no difference in mortality between patients prescribed carvedilol and those prescribed metoprolol [28]. Insulin induced hypoglycemia has been postulated to elicit an adverse sympathoadrenal response that predisposes to arrhythmia and death. This response is blunted by recurrent antecedent hypoglycemia or BB administration [47]. Thus, the sympathoadrenal, and presumably the cardiovascular response to hypoglycemia may rely upon a complex interaction of multiple factors, including duration of diabetes, insulin exposure and BB use and type, and requires further study. In contrast to hypoglycemia incidence, basal insulin use was not an effect modifier for BB associated mortality though effect estimates were unstable and definitive conclusions could not be drawn.

The present study has several limitations, owing to its retrospective nature and as a result can not be used to determine causality. The duration of diabetes, comorbidities other than renal function and etiology of death was unknown. A diagnosis of diabetes was not an inclusion criterion due to the limitations of using diagnosis codes for identifying at risk patients and because patients undergoing glucose monitoring with insulin orders were considered a more relevant population. The exclusion of patients who switched BB limits the external applicability of these results, particularly since the reason for switching was unknown. However, including such patients would not allow for the comparison of effects of specific agents. Other nonselective BB were excluded because of very small numbers and/ or unique mechanisms of action. It is important to note that $\beta-1$ selectivity theoretically decreases with increasing doses but doses were not collected for this study. 
The timing of hypoglycemia with respect to insulin doses and actual doses were also unavailable, though all patients had orders for insulin therapy. In addition, this study was unable to assess symptoms of hypoglycemia. In a previous study of 250 insulin requiring hospitalized patients, $45 \%$ of patients who had a glucose $<3.8 \mathrm{mmol} / \mathrm{L}$ were asymptomatic [27]. Despite these limitations, this is the largest study of BB use and hypoglycemia risk in hospitalized patients to date.

\section{Conclusions}

This study indicates that BB use is associated with increased odds of hypoglycemia in hospitalized insulin requiring patients but this was limited to patients who were not receiving basal insulin. Among basal insulin nonrecipients, hypoglycemia risk was greater with SBB compared to carvedilol. Carvedilol and SBB were associated with increased risk of hypoglycemia in patients without heart failure but not in patients with heart failure. Moreover, hypoglycemia is associated with increased hospital mortality among patients receiving $\mathrm{SBB}$, those receiving no $\mathrm{BB}$, but not among patients receiving carvedilol. Further study is needed to understand the role of previous insulin exposure and hypoglycemia associated with BB use and BB type.

\section{Supplementary information}

Supplementary information accompanies this paper at https://doi. org/10.1186/s12933-019-0967-1.

Additional file 1: Table S1. Relationship between BB and hypoglycemia in heart failure subgroups.

\section{Abbreviations}

BB: beta blocker; SBB: selective beta blocker; ICD: International Classification of Diseases; $\mathrm{Hypo}_{1 \text { day: }}$ any glucose $<3.9$ mmol/L within $24 \mathrm{~h}$ of admission; Hypo: any glucose $<3.9 \mathrm{mmol} / \mathrm{L}$ throughout hospitalization; $\mathrm{Hypo}_{\text {severe: }}$ any glucose $<2.2 \mathrm{mmol} / \mathrm{L}$ throughout hospitalization; OR: odds ratio; Cl: confidence interval.

\section{Acknowledgements}

The project was supported by Award Number UL1TR001070 from the National Center for Advancing Translational Sciences. The content is solely the responsibility of the authors and does not represent the views of the National Center for Advancing Translational Sciences or the National Institutes of Health.

\section{Authors' contributions}

KD developed the study protocol, obtained data, performed the statistical analysis. JM assisted in obtaining the dataset and prepared the final text for submission, CL assisted with data analysis and manuscript review, PB edited and revised the final text. All authors read and approved the final manuscript.

\section{Funding}

Not applicable.

\section{Availability of data and materials}

In accordance with institution policy on sharing data and research resources, the final research data from this study may be made available for research purposes under a limited data use agreement specifying criteria for data access, conditions for research use, privacy and confidentiality standards to ensure data security and prohibitions for manipulating data for the purposes of identifying subjects.

\section{Ethics approval and consent to participate}

The Institutional Review Board at The Ohio State University approved this study.

\section{Consent for publication}

Not applicable.

\section{Competing interests}

KD discloses research support from Sanofi Aventis, Novo Nordisk, Eli Lilly, consulting activities with Eli Lilly, and MannKind. JM, CL and PB have no competing interests to disclose.

\section{Author details}

${ }^{1}$ Division of Endocrinology, Diabetes \& Metabolism, The Ohio State University, 5th Floor McCampbell Hall, 1581 Dodd Drive, Columbus, OH 43210-1296, USA. ${ }^{2}$ Division of Endocrinology, Duke University, 30 Duke Medicine Circle, Durham, NC 22710, USA. ${ }^{3}$ The Ohio State University College of Medicine, $370 \mathrm{~W}$. 9th Ave, Columbus, OH 43210, USA. ${ }^{4}$ Division of Cardiovascular Medicine, The Ohio State University, 452 W. 10th Ave, Columbus, OH 43210, USA.

Received: 4 September 2019 Accepted: 10 November 2019 Published online: 27 November 2019

\section{References}

1. Swanson C, Potter D, Kongable G, Cook C. Update on inpatient glycemic control in hospitals in the United States. Endocr Pract. 2011;17(6):853-61.

2. Wexler DJ, Meigs JB, Cagliero E, Nathan DM, Grant RW. Prevalence of hyper- and hypoglycemia among inpatients with diabetes. A national survey of 44 US hospitals. Diabetes Care. 2007;30(2):367-9.

3. Farrokhi F, Klindukhova O, Chandra P, Peng L, Smiley D, Newton C, et al. Risk factors for inpatient hypoglycemia during subcutaneous insulin therapy in non-critically ill patients with type 2 diabetes. J Diabetes Sci Technol. 2012;6(5):1022-9.

4. Elliott MB, Schafers SJ, McGill JB, Tobin GS. Prediction and prevention of treatment-related inpatient hypoglycemia. J Diabetes Sci Technol. 2012;6(2):302-9.

5. Cobaugh DJ, Maynard G, Cooper L, Kienle PC, Vigersky R, Childers D, et al. Enhancing insulin-use safety in hospitals: practical recommendations from an ASHP Foundation expert consensus panel. Am J Health Syst Pharm. 2013;70(16):1404-13.

6. Boucai L, Southern WN, Zonszein J. Hypoglycemia-associated mortality is not drug-associated but linked to comorbidities. Am J Med. 2011:124(11):1028-35.

7. Curkendall S, Natoli J, Alexander C, Nathanson B, Haidar T, Dubois R. Economic and clinical impact of inpatient diabetic hypoglycemia. Endocr Pract. 2009;15(4):302-12.

8. Tsujimoto T, Sugiyama T, Shapiro MF, Noda M, Kajio H. Risk of cardiovascular events in patients with diabetes mellitus on $\beta$-blockers. Hypertension. 2017;70(1):103-10.

9. Hirsch IB, Boyle PJ, Craft S, Cryer PE. Higher glycemic thresholds for symptoms during $\beta$-adrenergic blockade in IDDM. Diabetes. 1991;40(9):1177-86.

10. Lager I, Blohme G, Smith U. Effect of cardioselective and non-selective beta-blockade on the hypoglycaemic response in insulin-dependent diabetics. Lancet. 1979;1(8114):458-62.

11. Kerr D, MacDonald I, Heller S, Tattersall R. Beta-adrenoceptor blockade and hypoglycaemia. A randomised, double- blind, placebo controlled comparison of metoprolol CR, atenolol and propranolol LA in normal subjects. Br J Clin Pharmacol. 1990;29(6):685-93.

12. Murad MH, Coto-Yglesias F, Wang AT, Sheidaee N, Mullan RJ, Elamin MB, et al. Drug-induced hypoglycemia: a systematic review. J Clin Endocrinol Metab. 2009;94(3):741-5.

13. Ramanathan R, Cryer PE. Adrenergic mediation of hypoglycemia-associated autonomic failure. Diabetes. 2011;60(2):602-6. 
14. Farhat R, Su G, Sejling A-S, Knight N, Fisher SJ, Chan O. Carvedilol prevents counterregulatory failure and impaired hypoglycaemia awareness in non-diabetic recurrently hypoglycaemic rats. Diabetologia. 2019;62(4):676-86.

15. Tsujimoto T, Sugiyama T, Noda M, Kajio H. Intensive glycemic therapy in patients with type 2 diabetes on $\beta$-blockers. Diabetes Care. 2016;39(10):1818-26.

16. Tsujimoto T, Yamamoto-Honda R, Kajio H, Kishimoto M, Noto H, Hachiya $R$, et al. Effectiveness of prior use of beta-blockers for preventing adverse influences of severe hypoglycemia in patients with diabetes: an observational study. Medicine. 2015;94(39):e1629.

17. Brutsaert E, Carey M, Zonszein J. The clinical impact of inpatient hypoglycemia. J Diabetes Complicat. 2014;28(4):565-72.

18. Tsujimoto T, Kajio H, Shapiro MF, Sugiyama T. Risk of all-cause mortality in diabetic patients taking beta-blockers. Mayo Clin Proc. 2018;93(4):409-18.

19. McGill JB, Bakris GL, Fonseca V, Raskin P, Messerli FH, Phillips RA, et al. Beta-blocker use and diabetes symptom score: results from the GEMINI study. Diabetes Obes Metab. 2007;9(3):408-17.

20. American Diabetes A. 15. Diabetes care in the hospital: standards of medical care in diabetes-2019. Diabetes Care. 2019;42(Suppl 1):S173-81.

21. American Diabetes A. 14. Management of diabetes in pregnancy: standards of medical care in diabetes-2019. Diabetes Care. 2019;42(Suppl 1):S165-72

22. Lleva RR, Thomas P, Bozzo JE, Hendrickson KC, Inzucchi SE. Using the glucometrics website to benchmark ICU glucose control before and after the NICE-SUGAR study. J Diabetes Sci Technol. 2014;8(5):918-22.

23. Maynard G, Schnipper JL, Messler J, Ramos P, Kulasa K, Nolan A, et al. Design and implementation of a web-based reporting and benchmarking center for inpatient glucometrics. J Diabetes Sci Technol. 2014;8(4):630-40.

24. Umpierrez G, Korytkowski M. Diabetic emergencies—-ketoacidosis, hyperglycaemic hyperosmolar state and hypoglycaemia. Nat Rev Endocrinol. 2016;12(4):222-32.

25. Pathak RD, Schroeder EB, Seaquist ER, Zeng C, Lafata JE, Thomas A, et al. Severe hypoglycemia requiring medical intervention in a large cohort of adults with diabetes receiving care in U.S. integrated health care delivery systems: 2005-2011. Diabetes Care. 2016;39(3):363-70.

26. Mathioudakis NN, Everett E, Routh S, Pronovost PJ, Yeh HC, Golden SH, et al. Development and validation of a prediction model for insulin-associated hypoglycemia in non-critically ill hospitalized adults. BMJ Open Diabetes Res Care. 2018;6(1):e000499.

27. Cardona S, Gomez PC, Vellanki P, Anzola I, Ramos C, Urrutia MA, et al. Clinical characteristics and outcomes of symptomatic and asymptomatic hypoglycemia in hospitalized patients with diabetes. BMJ Open Diabetes Res Care. 2018;6(1):e000607.

28. Zullo AR, Hersey M, Lee Y, Sharmin S, Bosco E, Daiello LA, et al. Outcomes of "diabetes-friendly" vs "diabetes-unfriendly" beta-blockers in older nursing home residents with diabetes after acute myocardial infarction. Diabetes Obes Metab. 2018;20(12):2724-32.

29. Thamer M, Ray NF, Taylor T. Association between antihypertensive drug use and hypoglycemia: a case-control study of diabetic users of insulin or sulfonylureas. Clin Ther. 1999;21(8):1387-400.

30. Shorr RI, Ray WA, Daugherty JR, Griffin MR. Antihypertensives and the risk of serious hypoglycemia in older persons using insulin or sulfonylureas. JAMA. 1997:278(1):40-3.

31. Group UKHS. Risk of hypoglycaemia in types 1 and 2 diabetes: effects of treatment modalities and their duration. Diabetologia. 2007:50(6):1140-7.

32. Giugliano D, Maiorino MI, Bellastella G, Chiodini P, Ceriello A, Esposito K. Efficacy of insulin analogs in achieving the hemoglobin A1c target of $<7 \%$ in type 2 diabetes: meta-analysis of randomized controlled trials. Diabetes Care. 2011;34(2):510-7.

33. Paelestik KB, Jespersen NR, Jensen RV, Johnsen J, Botker HE, Kristiansen SB. Effects of hypoglycemia on myocardial susceptibility to ischemia-reperfusion injury and preconditioning in hearts from rats with and without type 2 diabetes. Cardiovasc Diabetol. 2017;16(1):148.

34. Segel SA, Paramore DS, Cryer PE. Hypoglycemia-associated autonomic failure in advanced type 2 diabetes. Diabetes. 2002;51(3):724-33.

35. Mann SJ. Redefining beta-blocker use in hypertension: selecting the right beta-blocker and the right patient. J Am Soc Hypertens. 2017;11(1):54-65.

36. Reveno WS, Rosenbaum H. Propranolol and hypoglycaemia. Lancet 1968;1(7548):920.

37. Bolli G, de Feo P, Compagnucci P, Cartechini MG, Angeletti G, Santeusanio $F$, et al. Important role of adrenergic mechanisms in acute glucose counterregulation following insulin-induced hypoglycemia in type I diabetes. Evidence for an effect mediated by beta-adrenoreceptors. Diabetes. 1982;31(7):641-7.

38. Carey M, Gospin R, Goyal A, Tomuta N, Sandu O, Mbanya A, et al. Opioid receptor activation impairs hypoglycemic counterregulation in humans. Diabetes. 2017;66(11):2764-73.

39. Hsu CT, Liu IM, Cheng JT. Increase of beta-endorphin biosynthesis in the adrenal gland of streptozotocin-induced diabetic rats. Neurosci Lett. 2002;318(2):57-60.

40. Bakris GL, Fonseca V, Katholi RE, McGill JB, Messerli FH, Phillips RA, et al. Metabolic effects of carvedilol vs metoprolol in patients with type 2 diabetes mellitus and hypertension: a randomized controlled trial. JAMA. 2004;292(18):2227-36.

41. Basat O, Ucak S, Seber S, Oztekin E, Altuntas Y. After myocardial infarction carvedilol improves insulin resistance compared to metoprolol. Clin Res Cardiol. 2006;95(2):99-104.

42. Packer M, Bristow MR, Cohn JN, Colucci WS, Fowler MB, Gilbert EM, et al. The effect of carvedilol on morbidity and mortality in patients with chronic heart failure. U.S. Carvedilol Heart Failure Study Group. N Engl J Med. 1996:334(21):1349-55.

43. Hjalmarson A, Goldstein S, Fagerberg B, Wedel H, Waagstein F, Kjekshus J, et al. Effects of controlled-release metoprolol on total mortality, hospitalizations, and well-being in patients with heart failure: the Metoprolol CR/ XL Randomized Intervention Trial in congestive heart failure (MERIT-HF). MERIT-HF Study Group. JAMA. 2000;283(10):1295-302.

44. Everly MJ, Heaton PC, Cluxton RJ Jr. Beta-blocker underuse in secondary prevention of myocardial infarction. Ann Pharmacother. 2004;38(2):286-93.

45. Jonas M, Reicher-Reiss H, Boyko V, Shotan A, Mandelzweig L, Goldbourt $U$, et al. Usefulness of beta-blocker therapy in patients with non-insulindependent diabetes mellitus and coronary artery disease. Bezafibrate Infarction Prevention (BIP) Study Group. Am J Cardiol. 1996;77(15):1273-7.

46. Zaccardi F, Nystrup Husemoen LL, Thorsted BL, Webb DR, Paul SK, Davies MJ, et al. Selectivity of beta-blockers, cardiovascular and all-cause mortality in people with hypoglycaemia: an observational study. Nutr Metab Cardiovasc Dis. 2019;29(5):481-8.

47. Reno CM, Daphna-Iken D, Chen YS, VanderWeele J, Jethi K, Fisher SJ. Severe hypoglycemia-induced lethal cardiac arrhythmias are mediated by sympathoadrenal activation. Diabetes. 2013;62(10):3570-81.

\section{Publisher's Note}

Springer Nature remains neutral with regard to jurisdictional claims in published maps and institutional affiliations. 